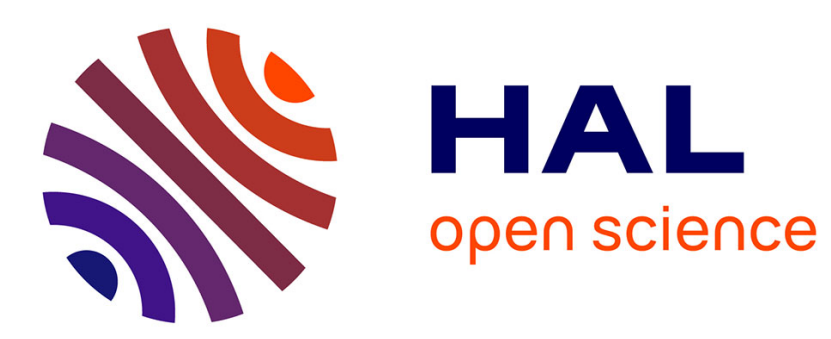

\title{
Medical Ethics and Therapeutic Knowledge from China as Contested Knowledge in Times of Globalization \\ Evelyne Micollier
}

\section{To cite this version:}

Evelyne Micollier. Medical Ethics and Therapeutic Knowledge from China as Contested Knowledge in Times of Globalization. Chiang Mai University Journal of Social Sciences and Humanities, 2015, 2 (2), pp.91-101. 10.12982/cmujASR.2015.0006 . halshs-01643647

\section{HAL Id: halshs-01643647 https://shs.hal.science/halshs-01643647}

Submitted on 21 Nov 2017

HAL is a multi-disciplinary open access archive for the deposit and dissemination of scientific research documents, whether they are published or not. The documents may come from teaching and research institutions in France or abroad, or from public or private research centers.
L'archive ouverte pluridisciplinaire HAL, est destinée au dépôt et à la diffusion de documents scientifiques de niveau recherche, publiés ou non, émanant des établissements d'enseignement et de recherche français ou étrangers, des laboratoires publics ou privés. 


\title{
Medical Ethics and Therapeutic Knowledge from China as Contested Knowledge in Times of Globalization
}

\author{
Evelyne Micollier
}

\begin{abstract}
Cluster Local Cutures and Global Health, IRD (Institut de Recherche pour le Développement/French Research Institute for Development), IRD UMI 233, INSERM 1175, Unit TransVIHMI, Montpellier, France

Currently stationed at IRD Laos, Vientiane, Lao PDR

Corresponding author. E-mail: evelyne.micollier@ird.fr
\end{abstract}

ABSTRACT

raming 'new ethics' within both Chinese and international char-
acteristics has become a pressing issue, while China's research and innovation policy encourages a turn towards a knowledge economy and a number of international/Chinese corporates delocalize industrial production to poorer countries offering cheaper labor. Plural health ideas, practices, and medical sciences are developing within the broader framework of the social and economic transformation of the Chinese society. Voices from civil society wish also to participate in the debates going on in the official, academic, and media spheres. On one side, ethno-(medical) ethics may be contested by most international development actors who strongly support a universalistic view of ethics; on the other side, local/national knowledge through the voices of a number of lay people's groups, locally-based and trained experts, and official actors seek ground for recognition. Of course, positions taken by all these stakeholders in terms of knowledge production, decision-making, and policy implementation may diverge widely. This paper will unveil a number of issues discussed in the 2000s relative to medical ethics, bioethics, and the New Health Reform guidelines and implementation. Finally, this paper will approach 'localized' biomedicine as contested knowledge through a few examples. My study is based on data collected using anthropological methodology and archival research.

Keywords: Ethics, Knowledge, Localization, Globalization, Medicine, Anthropology, China 


\section{INTRODUCTION}

In China, failures in health management between the early 1980s and early 2000s, due to market-oriented reforms, were officially assessed by the powerful Chinese State Council as 'basically unsuccessful', through the voice of the Center for Development Research and reported in "The Evaluation and Recommendations of Healthcare Sector Reform", July 2005, retrieved September, 15, 2011: http://www.drc.gov.cn/report. asp?t=report\&y=2005).

Qiu (2008) highlighted the key achievements and failures of the 1980s reform process and from his analysis, voiced the need for renewed interest in Confucian-style values of trust coming from the population-at-large; a very common complaint was that the art of ren (humaneness, beneficence; also known as humanism the Chinese way) had been transformed into the art of making money (Qiu, 2012). While more than $90 \%$ of the population-at-large acknowledged the failure of the reform by strongly disapproving it, more than $90 \%$ of healthcare professionals interviewed were very satisfied with it $(\mathrm{He}, 2005$ quoted by Qiu, 2012).

This situation prompted previously contained disapproving voices to express dissatisfaction in the academic arena; a number of medical professionals and social scientists argue that a solution might be to look back to medical ethics knowledge throughout Chinese history. Nonetheless, medical ethics in the context of culture is a form of local knowledge (Christakis,
1992); subsequently, it is worth further investigation and is capturing the attention of the academic arena at an international level. Further research is urgently needed as UNESCO programmes tackle the pressing and controversial issue of bioethics education, with a focus on Asia (Calderbank, 2008). Open debates and listening to all stakeholders in Asian societies have been limited in the region so far, while basic research and $R \& D$ in health sciences have developed, and new (bio)-technologies have become gradually available, raising new ethical issues.

My paper is organized in four parts: the first part builds on the 2000s health reform; the second one is about ethno-ethics in China and elsewhere; the third reports about ongoing discussions in China on medical ethics-related issues; the last one offers a few examples of contested knowledge production in Asian medicines.

\section{DISCUSSION}

\section{China's new health reform}

Since the late 2000s, the health reform designed to extend basic health insurance coverage and curb marketoriented healthcare, among other goals, has been progressing. A few chronological points about healthcare management in China need to be recalled here.

In the 1980s, a first round of reforms characterized by market-led deregulation and massive withdrawal of the State in terms of funding and control was gradually implemented. 
Both urban and rural healthcare systems had experienced drastic changes on the road to economic liberalization. Raising healthcare standards and reducing government's financial burden through market competition and rules were generally approved. Even though operational efficiency and health facility modernization and standardization improved some, one downside with regards to public health was an increased burden on individuals; in 2005, more than half of total healthcare expenditure (55.5\%) was borne by the people (Jiankang bao, 2005). In the 2000s, Chinese society experienced a new round of reforms, called 'new health reform', following the assessment of the failed reform and voices raised against the current healthcare system and its dysfunctions; a number of studies and heated debates revealed the importance of trust lying at the heart of patient-healer relationship, which had been badly damaged over the years. This situation signalled a rising societal interest in a widespread quest for better values, one that often translates into a reflection on past events. Confucian values and their possible application in medical ethics once again capture public attention in rethinking ethical issues and help to nourish the ongoing discussion.

Why did health reform become unavoidable for the Chinese government, and subsequently become a priority in public policy change? In the 2000s, health became the primary preoccupation of the Chinese population (Micollier, 2011b), as the people's voice, through the widespread use of what appeared to be a new common adage kanbing gui, kanbing nan ('indeed how expensive and difficult it is to consult') grew so loud that official actors could no longer ignore it. Many cases demonstrating the vulnerability and lack of trust of ordinary people (lao baixing) were circulated through all sorts of media, with whole families being ruined by a disease affecting one of its members, and patients not being taken care of because they could not afford the exorbitant fees (Micollier, 2011b; Zhai, 2012). All these examples prompted a widespread discussion followed by a heated debate on trust and its importance among Confucian virtues, as shown through the historical sets of medical ethics rules (detailed in $\mathrm{Mi}$ collier, 2015). A process of revitalization of historical medical ethics in the context of broader cultural repertoire change (increased interest for tradition, patrimony, both material and immaterial, knowledge, social ethics, etc.) is currently at work in China. The 2000s was a period of renewed interest for Chinese traditional and popular knowledge, know-how, and practice, with a focus on both material and immaterial patrimony, and on norms and rules, including social ethics for example.

Lack of trust was widely acknowledged and many urged restoring it in both the inter-subjective patienthealer relationship and, on a broader scale, in the population-at-large and within the health personnel network of relationships, as well as within the 
larger framework of the health system. Heuristically, most contributions from Chinese authors (Qiu, Zhai, Xia, Hou and Xiao) address these issues in a Special Issue of the International Journal of Bioethics concerning "Ethics-related issues in hospitals. French and Chinese situation compared", published in 2012 .

\section{About ethno-ethics in China and elsewhere}

Since the 1970s, four basic principles have influenced Western bioethics, though not without critical discussion. These became post-World War II international basic principles, namely autonomy, beneficence, nonmalfeasance, and justice (Beauchamp and Childress, 1983). In our globalized and multicultural society, since the 1980s, research in social sciences, and more specifically in anthropology, has brought a new light on the universalistic nature of a number of ethical principles, such as new interpretations about the four principles emanating from the Bellemont Report and North American Bioethics. The aim of these studies was to inform about the ethno-centric nature of bioethics, cultural diversity in societies, and issues regarding the application elsewhere of a Western-born ethical thought designed for biomedicine, as practiced and interpreted firstly in the West.

Lieban (1990) studied the medical ethics of traditional and popular healers from a comparative perspective, emphasizing the cultural differences, but also the similarities beyond cul- tures, approaching biomedical ethics from an inter-cultural perspective. His account of the Chinese context is based on Unschuld's (1979) work on medical ethics in Imperial China. A key hypothesis is that similarities in medical ethics do exist in various cultural contexts independent of each other. He takes the case of Western medicine and of traditional medicine in imperial China as significant examples. He argues that both contexts share one principle and two important ethical issues: the principle of beneficence and assistance, the relationship between the two values is perceived as contradictory-profit generated by the practice of medicine versus the altruism necessary for the practice; ethical issues concern the relationship between medical ethics and the process of professionalization.

McGréal (1991) investigated innovation and changes in Chinese medical ethics, comparing historical principles sets and post-1979 (Reform Era) sets.

Lieban (1990) builds on Beauchamp and Childress (1983) and Veatch (1981): "Beneficence, defined here in broad terms as a duty to promote the welfare of others, is a primary ethical principle of Western biomedicine, with roots that go back to the Hippocratic Oath". However, rather than drawing too hasty a conclusion, the notion of beneficence should be looked at more closely; the meaning of the Western notion of beneficence may diverge from the meaning of ren (humaneness, humanity) in Chinese. According to Tung (1994), reflecting 
the highest virtue, the character 仁 (ren) formed by 'two' and 'human' indicates that the body-self is part of a larger whole, more precisely of both another human being and/or of the natural environment. Such a cosmological dimension is not present in the Western notion of beneficence; the relationship of the human being to Nature is obviously very different in each context. In contrast, the principle of social ethics contained in the Chinese term is closer to the Western meaning.

Chinese sources quoted by Unschuld (1979) often mention the moral duty of helping others and of assisting sick people.

The first ethical issue concerns the contradiction inherent in medical practice between making a profit and being altruistic; tension between self-interest and philanthropy has been analyzed as the key paradox in medicine (Pellegrino, 1985).

The second ethical issue concerns medical ethics and the professionalization of medical practice. In the context of both China (Unschuld, 1979) and Western civilization (Freidson, 1970), the codes of medical ethics are tools serving a corporation guaranteeing a moral use of medicine and assuming responsibility for medical resources.

Ethno-ethics of medicine still needs to be explored; it "refers to moral tenets and problems of health care as they are conceived and reacted to by members of a society" (Lieban, 1990). Even though most studies about medical ethics from an inter-cultural perspective focus on cultural differences, the consensus is compulsory, because biomedicine has fully developed into global institutional medicine. However, such consensus and subsequent homogeneity through a standardization and institutionalization process is only apparent and superficial. Therefore, Kunstadter (1980) argued that, behind the scenes, the introduction of Western medicine and the spreading of its ethics is the main explanatory factor for such apparent homogeneity. Taking the example of India, he shows how traditional ethical systems have been ignored by Westernized medical institutions. However, biomedical ethics in non-Western countries inexorably experiences a process of adaptation to the norms and values of non-Western societies.

Kleinman (1995) argued that bioethics were 'westernized' from their emergence giving all rights to the individual, considering risks and benefits systematically and solely in terms of 'individual rights'.

If biomedical perspectives conflict with local norms and values, serious ethical issues emerge which need to be discussed and negotiated in context. From the field of health education to research and development sectors, biomedicine is always adjusted in context; such a localization process generates discussion and tensions regarding ideas (knowledge at work and its production) and practice (clinical, care, healing aspects, research), including, of course, in the field of ethics (see for instance, Micollier 
2007, Micollier 2011a).

\section{Medical ethics in 2000s China: issues commonly discussed}

The Chinese situation will be informed by informed consent, confidentiality, and the role of the family, with a focus on the patient-healer relationship. The modalities and management of this relationship lie at the heart of medical ethics considerations. As is the case in many countries, family decision-making is the normative way of dealing with health and illness in China. This has been recognized and recommended within the framework of the national medical ethics scheme. When a family member is affected by a distressful situation, all members perceive themselves as sick and the most vulnerable member is the one who effectively puts the others at risk; from this insider's view, the observer can understand why the decision is often not individual, but collective. This attitude questions the value of confidentiality and the role of the individual in the consent procedure. However, confidentiality and privacy are fundamental values in the West relative to individual decision-making, and a clear line is drawn between the private and public sphere. The emergence of a standardized procedure for informed consent - indeed, the very idea of informed consent, bring us back to the roots of contemporary/Western bioethics, namely the Nuremberg Code, the Bellemont Report, and the North American Rules.
Another issue concerns international normative rules that have not been sufficiently contextualized; informed consent is required for any treatment intervention and tragic cases like the one cited by the sociologist Xia (2012) are not rare: a pregnant woman lost her life due to lack of health information and sufficient awareness on the part of her husband, who refused to sign the informed consent, as occurred in Beijing in 2007.

Among others voices, Zhai (2012) argues that while medicine has become a big business, the goals and management of medical services need to be changed to restore people's trust in what has turned into a highly damaged patient-healer relationship. Cases of aggression, attacks targeting healthcare personnel, and personnel wearing helmets to protect themselves, became common in the 2000s (case examples by Xia, 2012). Xia gathered official data from surveys conducted in the 2000s in Shanghai, Beijing, and Hunan Province; the data consistently showed a badly damaged therapeutic relationship, with the number of incidents, medical malpractice, medical disputes, and medical staff being orally insulted or physically beaten, increasing dramatically. Results from the Fourth National Health Service Survey completed in 2008 indicated that more than twenty percent of medical staff surveyed had endured oral insults, almost one percent violence and close to six percent threats, either orally or through mailed letters (Xia, 2012). 
Xia, Zhai, Qiu, Hou, and Xiao all focused on an increased/newly emerged "unbalanced position of negotiation" (Xia, 2012), or on the asymmetric power relationship (Zhai, 2012) between doctors and patients, as a key factor explaining why the relationship had undergone such a dramatic change. Interestingly enough, this point is what the Nuremberg Code (1947) elaborated upon after a post-World War II US military court aimed to initially reduce the power imbalance between medical staff, institutions, and patients, suggesting that in a more egalitarian power relations model, the decision-making power of the patient, who is intrinsically recognized as vulnerable, should increase. This is how and why the procedure of informed consent, or "une capacité légale totale à consentir" (a complete legal capacity to consent), was first created - and continues to be strongly recommended. "Complete legal capacity" of the individual means that the two parties are equal; subsequently, in order to facilitate the analysis of risks and benefits for the individual concerned, sufficient and detailed information concerning the medical service should be provided (Ambroselli, 1994).

Following a Foucaldian reading (Foucault, 1976), for the benefit of the patient, the population-at-large, and, more specifically, vulnerable groups, the whole process in the end should decrease the 'bio-political' power of the medical actors. Therefore, a form of 'governmentality' on bodies and individuals is at work bringing about a subtle way of taking control on persons and groups.

East-west exchanges and shifts in knowledge production: a few examples

At this juncture, I shall give a few examples of how East-West exchanges in terms of knowledge production are being reshaped. One could hardly claim that localized biomedicines are not contested anymore, but at least the ones elaborated and practiced in some Asian countries like China and Southeast Asia (Vietnam, Thailand) are less contested. The discovery and the long journey of antimalarial treatments (ACTs, or Artemisinine-based Combination Therapies) towards international acceptance are considered as paradigmatic examples of this change, including of what is politically and socially at stake.

The 'story' of anti-malarial ACTs. The WHO (World Health Organization) recommended ACTs for global use in 2004 while China had fully (re-)emerged as an economic power. ACTs can be briefly described as a pharmacological success in integrative medicine combining a purified traditional' medicine, namely 'artemisinin' extracted from Artemisia annua L., a plant from Chinese Materia Medica, with a biomedical product. These latter are diverse derivatives from and/ or previously used biomedical drugs such as Chloroquine and Mefloquine. The use of these biomedical products is not recommended anymore because of drug-resistance issues. Artemisinin extract was discovered by Chinese 
researchers, Tu Youyou and her team from Beijing, in the 1970s.

In this case, [it's] not a dispute between traditional medicine and Western medicine but the nonacceptance [late acceptance!] by the international scientific community of the results of Western medicine as practised in a developing country of Southeast-Asia [referring to the Thai response to malaria in the 1980s] and in communist China (Power, 1997)

A few dates are considered key events on the route towards international recognition of ACTs' efficacy. The Chinese principal investigator in the long-term research explained the discovery of artemisinin in Nature Medicine (Tu, 2011). Two prestigious awards in science were awarded to Chinese researchers for their role in ACTs. In 2011, Tu Youyou and her team were awarded the Lasker Award, one of the most prestigious international awards in medical clinical research, for the discovery of Artemisinin extract in 1972. In 2009, Zhou Yiqing, principal investigator and his team, were awarded the European Inventors of the Year Award in the non-European countries category for developing the first ACT (Coartem, 1985). Last but not least, Tu received the Nobel Prize in Medicine in 2015, the first Chinese researcher to have been awarded the most prestigious international prize within a scientific field.
Less contested Asian medicine(s): significant steps. Thailand has independently assessed, licensed, and been using Chinese drugs for a long time. Since 1928, courses in Thai remedies and Chinese materia medica were included in biomedical sciences (Power, 1997).

Knowledge and practice components of Chinese medicine gained international recognition with a UNESCO World Knowledge Heritage label (2010). A UN-promoted Yoga Day (2015) has been recently proclaimed: "By proclaiming 21 June as the International Day of Yoga, the General Assembly has recognized the holistic benefits of this timeless practice and its inherent compatibility with the principles and values of the United Nations" (Ban Ki-Moon, 2014, Dec. 11, http://www.un.org/ en/events/yogaday/).

Researching the globalization process of Chinese medicine, De Bruyn and Micollier (2011) attempted to sketch a typology of ideological, epistemological, political, economic, and educational issues that come together around Chinese medicine in its transmission process while considering Chinese medicine as a world heritage. The aim was to identify a number of issues regarding its future.

Since 1992, Indian and Chinese contemporary pharmacopeia, including both traditional medicines and biomedical pharmaceuticals, are registered and regularly updated at the World Health Organization (Micollier, 2011a). Specific R\&D models and pharmaceutical inno- 
vations are in progress in industrial Asian medicine(s) (see for instance, Micollier, 2013).

A last example from Lao PDR, a department of Chinese medicine with a focus on acupuncture is currently integrated in the national referral hospital (Mahosot Hospital) in Vientiane. As for research in partnership, a significant bilateral research agreement in medical sciences with Chinese institutions was approved in 2012.

\section{CONCLUSION}

Asian medicines ideas and practices, more specifically industrial pharmaceuticals, but also well-being and self-cultivation practices, are disseminating at a global level among actors and institutions, within the framework of 'integrated' and 'integrating' healthcare systems. These latter bring other medical traditions into biomedicine - more specifically in fields of preventive medicine, occupational and rehabilitation medicine, well-being and corporal practices, pain management and palliative care. Nonetheless, ethno-ethics and ethical governance from elsewhere, namely not rooted in the post-colonial order, are still scarcely taken into account in this transforming process. In the end, such processes may produce 'post-Western' bodies of knowledge and practice in a number of fields investigated and, therefore, contribute to transforming societies on a global scale.

\section{ACKNOWLEDGEMENTS}

This study was part of a research project (2006-2011), Evelyne Micollier) carried out in partnership withe the Peking Union Medical College/ Chinese Academy of Medical Services (PUMC/CAMS) at the Human and Social Sciences Department and the Centre for Bioethics, and Tsinghua University, Beijing. The Funding was provided by the CEFE (French Centre for Research on Contempory China), Hong Kong, and the IRD.

\section{REFERENCES}

Ambroselli, C. (1994). L'éthique médicale (Medical Ethics). Paris: PUF. Beauchamp, T.L., and Childress, J.F. (1983). Principles of Biomedical Ethics. New-York: Oxford University Press.

Calderbank, D. Chief Ed. (2008). Asia-Pacific Perspectives on Bioethics Education. Bangkok: UNESCO Asia and Pacific Regional Bureau for Education: 203.

Christakis, N.A. (1992)."Ethics are local: engaging cross-cultural variation in the ethics for clinical research." Social SciencedMedicine, 35(9), 1079-1091. doi: 10.1016/0277-9536(92) 90220-K

De Bruyn, P.H., and Micollier, E. (2011). "The Institutional Transmission of Chinese Medicine: A Typology of the Main Issues." China Perspectives, 86, 23-32.

Foucault, M. (1976). Histoire de la sexualité (History of Sexuality): Vol. 1. Paris: Gallimard. 
Freidson, E. (1970). Profession of Medicine: A Study of the Sociology of Applied Knowledge. New-York: Harper and Row.

He, T.Q. (2005). 'Two types of satisfaction degree". Jiankang bao (Health News), September 1, 4.

Hou Xiaoshuo, \& Xiao Ling. (2012).

"An analysis of the changing doctor-patient relationship in China." International Journal of Bioethics, 23(2), 83-94. doi: 10.3917/jib.232.0083

Jiankang bao (Health News), July 1, 2005 (Chinese Ministry of Health publication).

Kleinman A. (1995). "Anthropology of Bioethics." in A. Kleinman Writing at the Margin. Discourse between Anthropology and Medicine. Berkeley, University of California Press, 41-67.

Kunstadter, P. (1980).“Medical Ethics in Cross-Cultural and MultiCultural Perspective." Social Science \& Medicine 14B, 289-296. doi: 10.1016/0160-7987(80) 90054-X

Lieban, R.W. (1990). "Medical Anthropology and the Comparative Study of Medical Ethics." In Weisz G. ed. Social Science Perspective on Medical Ethics, Dordrecht, Kluwer Academic Publishers, 221-239. doi: 10.1007/978-94-009-19303_12

McGréal, I.P. (1991). “The new dimensions of Chinese Medical Ethics." Journal of Chinese Philosophy 18, 161-168. doi: $10.1111 / \mathrm{j} .1540-$ 6253.1991.tb00624.x
Micollier, E. (2007). "Facettes de la recherche médicale et de la gestion du VIH-sida dans le système de santé chinois: un autre exemple d'adaptation locale de la biomédecine" ('Aspects of medical research and HIV-AIDS management in Chinese healthcare system: another example of biomedicine local adaptation'). Sciences Sociales et Santé 25(3), 31-39. doi: 10.3917/sss.253.0031 Micollier, E. (2011a). "Un savoir thérapeutique, hybride et mobile. Eclairage sur la recherche médicale en médecine chinoise en Chine aujourd'hui" ('A hybrid and circulating therapeutic knowledge. Chinese medical research in China today'). In L. Pordié éd. 'Savoirs thérapeutiques asiatiques et globalisation' ('Asian therapeutic knowledge and globalization'). Revue d'Anthropologie des Connaissances (Journal of Knowledge Anthropology), 5(1), 41-70. doi: 10.3917/rac.012.0041

Micollier, E. (2011b). "Pourquoi une réforme du système de santé est-elle urgente?" ('Why has health reform become a pressing issue in China?'). In F. Duléry éd. Aujourd'hui la Chine (China Today), Montpellier, CNDP (Centre National de Documentation Pédagogique), CRDP (Centre de Recherche de Documentation Pédagogique), 88-91.

Micollier, E. (2012). "Transcultural discussion in bioethics drawn from research experience in China: building up a theoretical and 
methodological framework for further research cooperation" (in French). International Journal of Bioethics/Journal International de Bioéthique, 23(2), 105-116.

Micollier, E. (2013). "Nouveaux produits de la pharmacopée chinoise contemporaine: $\mathrm{R} \& \mathrm{D}$, définition et socialité en réseaux" ('New Products of the contemporary Chinese pharmacopoeia: $\mathrm{R} \& \mathrm{D}$, definition, and actors networks sociality'). Autrepart, 63, 69-88.

Micollier, E. (2015). "Ethno(medical) ethics in globalizing China: Tracing local knowledge and adaptation of biomedicine." International Journal of Bioethics and Science Ethics, 26(4), 97-112. Pellegrino, E.D. (1985). "The Virtuous Physician and the Ethics of Medicine." In E.E. Shelp ed. Virtue and Medicine, Dordrecht, D. Reidel, 237-255.

Power, H. (1997). "Drug-resistant malaria: a global problem and the Thai response". In A. Cunningham and A. Bridie Eds. Western medicine as contested knowledge, Manchester University Press, Manchester and New York, 262286.
Qiu, R. (2008). "Confucius Trust, Market and Health Reform". In J. Tao ed. China: Bioethics, Trust, and the Challenge of the Market, New York, Springer.

Qiu, R. (2012). "Healthcare sector reform and its influence on public hospitals in Mainland China." International Journal of Bioethics, 23(2), 17-24. doi: 10.3917/jib. 232.0015

Tu, Y. (2011). "The discovery of artemisinin (qinghaosu) and gifts from Chinese medicine, Nature Medicine, 17, 1217-1220.

Tung, M.P.M. (1994). "Symbolic Meanings of the Body in Chinese Culture and 'Somatization'." Culture, Medicine and Psychiatry, 18(4), 483-492. doi: 10.1007/ BF01565850

Veacht, R.M. (1981). A Theory of Medical Ethics. New-York: Basic Books.

Unschuld, P.U. (1979). Medical Ethics in Imperial China: A Study in Historical Anthropology. Berkeley: University of California Press.

Xia, G. (2012). "Undue game of baseline principles: the physicianpatient relationship from a bioethical perspective." International Journal of Bioethics, 23(2), 77-81.

Zhai, X. (2012). "Medicine: Business or Profession?" International Journal of Bioethics, 23(2): 25-32. Zhou, Y. (2009), WHO Bulletin, 87: 10 . 
